Review

\title{
A Competing Neurobehavioral Decision Systems model of SES-related health and behavioral disparities
}

\author{
Bickel W.K. ${ }^{\text {a, }}$, Moody L. ${ }^{a}$, Quisenberry A.J. ${ }^{\text {a }}$, Ramey C.T. ${ }^{\text {a }}$, Sheffer C.E. ${ }^{b}$ \\ a Virginia Tech Carilion Research Institute, Roanoke, VA 24016, USA \\ b The City College of New York, New York, NY 10031, USA
}

\section{A R T I C L E I N F O}

Available online 6 July 2014

\section{Keywords:}

Competing Neurobehavioral Decision Systems

Executive function decision system

Impulsive decision system

SES gradient

Health disparities

\begin{abstract}
A B S T R A C T
We propose that executive dysfunction is an important component relating to the socio-economic status gradient of select health behaviors. We review and find evidence supporting an SES gradient associated with (1) negative health behaviors (e.g., obesity, excessive use of alcohol, tobacco and other substances), and (2) executive dysfunction. Moreover, the evidence supports that stress and insufficient cognitive resources contribute to executive dysfunction and that executive dysfunction is evident among individuals who smoke cigarettes, are obese, abuse alcohol, and use illicit drugs. Collectively these data support the dual system model of cognitive control, referred to here as the Competing Neurobehavioral Decision Systems hypothesis. The implications of these relationships for intervention and social justice considerations are discussed.
\end{abstract}

(c) 2014 Elsevier Inc. All rights reserved.

\section{Contents}

What is the extent of the SES gradient among important health behaviors that negatively affect health? . . . . . . . . . . . . . . . . . 38 Cigarette smoking . . . . . . . . . . . . . . . . . . . . . . . . . . . . . . . . . . . . . . 39

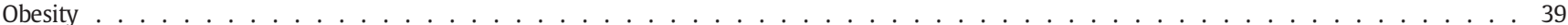

Alcohol and illicit drug use . . . . . . . . . . . . . . . . . . . . . . . . . . . . . . . . . . 39

What is the evidence that SES is associated with executive dysfunction? . . . . . . . . . . . . . . . . . . . . . . . . . 39

What is the evidence that stress contributes to executive dysfunction? . . . . . . . . . . . . . . . . . . . 40

What is the evidence of executive dysfunction among individuals who smoke cigarettes, are obese, abuse alcohol, and use illicit drugs? . . . . . . . . . 40

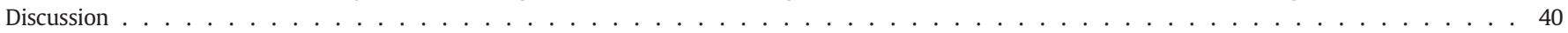

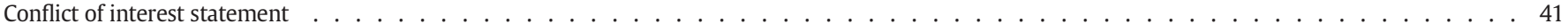

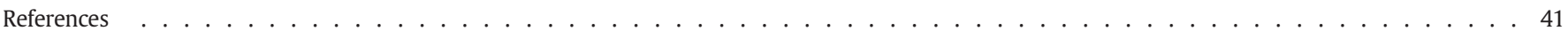

Socioeconomic disparities in overall health, morbidity, and mortality are pervasive and prodigious, and remain largely unaffected with current approaches (Adler and Rehkopf, 2008). In western society a strong inverse relationship exists between employment grade and mortality among British civil service workers (Marmot et al., 1984) in addition to educational level and mortality among American men (Kitagawa and Hauser, 1973). The relationship between SES and health status shows a relatively smooth monotonic gradient that extends from those at the lowest to those at the highest end of the socioeconomic spectrum and thus, is not entirely accounted for by poverty-induced deprivation or access to health care (Adler and Stewart, 2010b).

* Corresponding author at: Addiction Recovery Research Center, Virginia Tech Carilion Research Institute, Virginia Tech, 2 Riverside Circle, Roanoke, VA 24016, USA

E-mail address: wkbickel@vtc.vt.edu (W.K. Bickel).
In health research, SES is a broad construct describing relative access to the basic resources required to achieve and/or maintain good health (Galobardes et al., 2006a, 2006b; Shavers, 2007). Given that the SES construct is complex consisting of numerous measures, indicators, or proxies, it demonstrates that no single measure is best for all studies and populations. Individual measures of SES have varying degrees of relevance depending on context. Measures often used include educational achievement, income, occupation, and wealth; each of which assesses different, albeit related, aspects of SES. Measures composed of multiple components often provide more multifaceted assessments (Galobardes et al., 2006a, 2006b). Educational achievement is a widely used indicator of SES in health research and is particularly useful in relatively homogeneous populations (Miech and Hauser, 2001) where it is likely to capture important aspects of lifestyle and behavior that have a significant effect on future occupational opportunities and earning 
potential (Galobardes et al., 2006a, 2006b). Educational achievement, however, comprises a variety of influences, which individually contribute to an educational gradient in health behaviors. For example, material resources account for about $30 \%$ of the education gradient in health behaviors, $10 \%$ of knowledge, and $20 \%$ of cognitive ability (Cutler and Lleras-Muney, 2010). Household income, often highly correlated with educational achievement, is considered the single best indicator of material living standards (Galobardes et al., 2006a, 2006b) and is a particularly useful SES indicator for a family's primary wage earner (Adler and Newman, 2002). The components of SES are dynamic, multidimension$\mathrm{al}$, and complex reinforcing the appreciation of its multiple pathways for achieving and maintaining good health.

Conceptual models propose that socioeconomic health disparities emerge because of higher levels of stress, less access to physical and environmental resources, greater environmental constraints, fewer affective and cognitive resources, and important health behaviors associated with preventable death, such as cigarette smoking, eating and physical activity, and alcohol and illicit drug use (Adler and Newman, 2002; Adler and Stewart, 2010a; Gallo and Matthews, 2003). Taken together, these health behaviors account for the vast majority of preventable death and disease in the U.S. (see Table 1, National Research Council, 2013; Rimm et al., 1999; Schroeder, 2007; Mokdad et al., 2004). While the relationship between SES and health behaviors is dynamic and multiply determined, an important commonality among all these health behaviors is that they entail repeatedly choosing to engage in behaviors despite long-term negative outcomes, and oftentimes, despite serious intentions to change the behaviors and many attempts to do so. We propose that the experience of SES contributes to a particular type of decision-making that serves as a conceptual and functional link between SES and health behaviors. We propose that the tendency to choose immediate over long-term rewards is likely to contribute to the development and maintenance of unhealthy behaviors. Alternatively, the tendency to choose long-term over immediate rewards is likely to contribute to the development and maintenance of healthy behaviors. We propose that the environment associated with lower SES perpetuates the former decision-making and restricts tendencies toward the latter thus accounting for a portion of the socioeconomic gradient in health behaviors and perhaps offers new targets for prevention and treatment interventions.

The model we use to describe and interpret this decision-making style is the Competing Neurobehavioral Decision Systems model (Bickel et al., 2012). This model views decision-making processes as resulting from the competing influences from (1) the impulsive decision system, embodied by the limbic and paralimbic brain regions, which engenders individuals to choose immediate reinforcers; and (2) the executive decision system, embodied in parts of the prefrontal cortices, which engenders individuals to favor long-term outcomes and inhibit impulses. The balance between these systems is affected by a variety of factors including perceived need, motivation, context, and perceived stress level. This model is grounded in the work of Bechara (2005) and Jentsch and Taylor (1999) and consistent with a variety of dual decision system models. For example, Jentsch proposes inhibitory and impulsive systems (Jentsch and Taylor, 1999) and Strack and Deutsch outline reflective and impulsive systems (Strack and Deutsch, 2004) as conceptualizations of normal behavior (see Evans

Table 1

Annual U.S. mortality rates and cost of alcohol use, illicit drug use, cigarette smoking, over eating and obesity (McGinnis and Foege, 1993; National Institute on Drug Abuse, 2012; U.S. Department of Health and Human Services, 2001).

\begin{tabular}{lcl}
\hline Negative health behavior & Mortality & Cost \\
\hline Alcohol use & 88,000 & $\$ 223.5$ billion \\
Illicit drug use & 20,000 & $\$ 600$ billion \\
Cigarette smoking & 440,000 & $\$ 96$ billion \\
Over eating/obesity & 300,000 & $\$ 147$ billion \\
\hline
\end{tabular}

and Stanovich, 2013, for a review of the different attributes of dual systems). The Competing Neurobehavioral Decision Systems hypothesis provides a conceptual framework within which we can conceptualize how neurological dysfunction of the dual system can lead to behaviors with negative health outcomes (see Fig. 1 and Table 2).

We propose that the experience of SES affects the balance of these two competing systems. When the Competing Neurobehavioral Decision Systems are in regulatory balance, individuals demonstrate the capacity to adaptively attend to temporally arrayed events, weigh input from the competing systems, and establish and follow through with decisions that have healthy immediate and long-term outcomes. When the system is dysregulated or out of balance, perhaps due to stress or lack of cognitive resources, the capacity to establish and follow through with decisions that have healthy immediate and delayed outcomes is constrained. When the executive decision system is less effective or compelling than is required for adaptive decision-making, we describe this as executive dysfunction. We will explore how the Competing Neurobehavioral Decision Systems can explain the development and maintenance of negative health behaviors by the tendency to choose immediate over long-term rewards and how this tendency is rooted in neurological functioning. To achieve this end, we present a summary of the literature with reference to these important questions:

1) To what extent is the SES gradient a contributing factor in negative health behaviors (obesity, alcohol, tobacco, and substance abuse and dependence)?

2) What is the evidence that the SES gradient is associated with executive dysfunction?

3) What is the evidence that stress and insufficient cognitive resources contribute to executive dysfunction?

4) What is the evidence of executive dysfunction among individuals who smoke cigarettes, are obese, abuse alcohol, and use illicit drugs?

Finally we briefly discuss potential prevention opportunities and treatment interventions that may reduce the disparities seen across the SES gradient in decision-making and the implications for advancements in social justice.

\section{What is the extent of the SES gradient among important health behaviors that negatively affect health?}

Cigarette smoking, obesity, and alcohol and illicit drug use, are the major causes of preventable death and disease in western society.



Fig. 1. Conceptual model of relationship between SES gradient, negative health behaviors, and the Competing Neurobehavioral Decision Systems. As SES increases, the risk of negative health behaviors decreases linearly. One explanation for this relationship is a regulatory imbalance between the competing neurobehavioral decision systems. As shown, the impulsive limbic system may be relatively hyperactive and the executive prefrontal system relatively hypoactive in lower SES individuals. 
Table 2

Theoretical description of the different components of each structure in the Competing Neurobehavioral Decision Systems (Bickel et al., 2012).

\begin{tabular}{|c|c|c|}
\hline & Impulsive system & Executive system \\
\hline Embodied & Limbic and para-limbic brain regions & Prefrontal cortex \\
\hline Function & Valuation of immediate outcomes & Valuation of delayed outcomes, planning, memory \\
\hline Health characteristics & Regulatory balance & Regulatory balance \\
\hline Disease characteristics & Relatively hyperactive & Relatively hypoactive \\
\hline
\end{tabular}

They have different etiologies and long-term health consequences, but exhibit significant similarities in the socioeconomic pattern of prevalence rates.

\section{Cigarette smoking}

The prevalence of smoking has steadily declined since the initial reports that it negatively affects health raised public awareness; however the decline in prevalence has had a remarkably different rate among higher and lower SES groups. At present, the prevalence of cigarette smoking demonstrates a significant socioeconomic gradient (BRFSS data - Centers for Disease Control and Prevention, 2013). Lower SES groups smoke at 3 to 4 times the prevalence of higher SES groups making tobacco use one of the greatest contributors to health disparities (BRFSS - Centers for Disease Control and Prevention, 2012). While motivation to quit and attempts to quit show no socioeconomic gradient, lower SES groups are less likely to successfully quit once they begin smoking even when provided with a variety of treatments and treatment modalities (Agrawal et al., 2008; Barbeau et al., 2004; Centers for Disease Control and Prevention, 2005; Fagan et al., 2007; Ferguson et al., 2005; Kandel et al., 2009; Kotz and West, 2009; Reid et al., 2010; Sheffer et al., 2012b; Trinidad et al., 2011; Varghese et al., 2014; Wetter et al., 2005). At present, tobacco use is the leading contributor to health disparities in the U.S. and elsewhere, and unlike many other health disparities, tobacco-related cancer health disparities actually appear to be increasing (Jha et al., 2006; Kanjilal et al., 2006; Mokdad et al., 2004).

Obesity

In western culture obesity is generally recognized as an unhealthy condition and it demonstrates a consistent negative linear relationship with SES (BRFSS - Centers for Disease Control and Prevention, 2012). This relationship is the reverse of that observed in some developing countries where food scarcity contributes to a positive relationship between SES and obesity (Sobal and Stunkard, 1989). At present, the prevalence of obesity demonstrates a significant socioeconomic gradient (BRFSS data - Centers for Disease Control and Prevention, 2013). About one-third of the lower SES groups are obese while about onequarter to one-fifth of the higher SES groups are obese (BRFSS Centers for Disease Control and Prevention, 2012). The negative relationship between SES and the prevalence of obesity is stronger and more consistent among western women than men, possibly indicating that SES is associated with different cultural norms among different SES groups (Wardle et al., 2002). Alternatively, SES might also be related to gender-specific roles and the socioeconomic positioning of women. Women continue to earn significantly less than men for the same jobs and continue to shoulder a greater burden of household and childrearing responsibilities (Bianchi and Milkie, 2010). Women are more likely to be of lower socioeconomic status and live and raise children in poverty (U.S. census). Consequently, increased responsibilities of child rearing combined with the stress of managing limited resources might have a more significant effect on obesity-related behaviors, such as physical activity and eating an obesogenic diet, among women than among men. Perceived stress is consistently related to obesogenic dietary behaviors among both men and women (Barrington et al., in press). The negative relationship between SES and obesity is also greater among older individuals, suggesting that the effects of SES on obesity-related behaviors are, perhaps, cumulative (Baum and Ruhm, 2009).

\section{Alcohol and illicit drug use}

The vast majority of individuals who drink alcohol and/or try illicit substances do so without negative health outcomes. However, significant negative linear relationships are observed between SES and alcohol and illicit drug use prevalence, health problems, and mortality (Anthony et al., 1994; Buka, 2002; Curran et al., 1999; Goodman and Huang, 2002; Harder and Chilcoat, 2007; Makela, 1999; van Oers et al., 1999, BRFSS - Centers for Disease Control and Prevention, 2012). The negative relationship between drug use and SES is most robust in those countries with the largest socioeconomic differences in wealth. For example, Japan and Finland have some of the smallest socioeconomic differences in wealth and the lowest proportion of the population participating in illicit drug use; whereas, the United States and United Kingdom have the greatest differences in wealth and the highest proportion of the population participating in illicit drug use (Wilkinson and Pickett, 2011). The greater proportion of alcohol and illicit drugrelated problems and mortality are accounted for by higher rates of alcohol and substance abuse or dependence in lower SES groups (Parker and Harford, 1992).

\section{What is the evidence that SES is associated with executive dysfunction?}

Conceptual models posit that executive function is embodied in the prefrontal cortices. Many of the models are very similar with significant overlap in the range and type of executive function abilities described and the neurological correlates of specific functions (Chan et al., 2008; Hackman and Farah, 2009). Bickel et al. (2012) provide a comprehensive model that is particularly useful for understanding decisionmaking comprised of eight systems: attention, behavioral flexibility, behavioral inhibition, planning, future valuation, working memory, control of affective states, and metacognitive processes.

Unlike most models of executive function, the Bickel et al. (2012) model includes future valuation, which is the ability to project value into the future. Future valuation is often assessed by delay discounting tasks, which assess the decline in value of a reward as a function of time. Delay discounting, using psychophysical titration procedures (Bickel and Marsch, 2001; Hackman et al., 2010), is a frequently used and highly validated research tool (Bickel et al., 2012). Extreme discounting signals an inability to modulate value by time, and is often an indicator of executive dysfunction and/or functional or neurological impairment. Surveys of large samples of individuals $(n=42,863)$ show that lower SES groups tend to discount the value of future rewards more than higher SES groups (Reimers et al., 2009; see Green et al., 1996) suggesting a constrained capacity to modulate future valuation. Delay discounting using psychophysical titration procedures shows a consistent relationship between discounting and educational attainment (Jaroni et al., 2004; Lee et al., 2013), while use of truncated methods has failed to find that relationship (Cutler and Lleras-Muney, 2010).

The development of many executive function abilities including visuospatial skills, declarative memory, working memory, and cognitive control, appears to be affected by SES (Noble et al., 2007). The inverse 
relationship between executive dysfunction and SES is noticeable in the early academic career of children (Hackman et al., 2010), persists across the lifespan (Green et al., 1996; Richards and Wadsworth, 2004), and appears to be influenced and/or ameliorated by modifiable environmental factors (Mani et al., 2013). Working memory, cognitive control, and language skills demonstrate a positive relationship with SES in children as young as 6 months old (Farah et al., 2006; Hackman et al., 2010; Lipina et al., 2005). However, not all executive function abilities are dramatically affected by SES. For example, visual cognition appears to have only a moderate relationship with SES (Farah et al., 2006). Although not an executive function ability per se, it is worth noting that differences in reward processing as a function of SES are not observed (Farah et al., 2006) suggesting that the reward-seeking impulsive decision system is not deficient in lower SES individuals.

Language ability, a component of some models of executive function (Hackman and Farah, 2009), shows significant positive relationships with SES, similar to most executive functions (Farah et al., 2006; Fluss et al., 2009; Hackman and Farah, 2009; Hackman et al., 2010; Perkins et al., 2013). For example, $21 / 2$ year old children raised in professional families used, on average, 1116 unique words, while children from working class families used 749 unique words, and children living in homes receiving welfare benefits used 525 unique words (Hart and Risely, 1995).

Finally, a restriction of resources appears to have an immediate impact on certain executive functions. A real-world extension of laboratory findings showed that lower SES groups demonstrate significant declines in executive function abilities in high-cost, high stress conditions (Mani et al., 2013). Executive functioning was assessed in a sample of sugar cane farmers in India who naturally experience significant variability in financial resources throughout the year. The farmers demonstrated decreased attention and reasoning abilities during real-world conditions with decreased financial security.

\section{What is the evidence that stress contributes to executive dysfunction?}

Stress and stress regulation are significant components in biopsychosocial models of health, have a long history of being associated with the development of disease (Juster et al., 2010; Schulz et al., 2012), and are prominent in models of socioeconomic health disparities (Jackson et al., 2010). All individuals experience external events as stressful to varying degrees and evidence indicates that perceived stress contributes to differences in executive function ability. Stress regulation includes critical decision-making such as the modulation of stress exposure and the performance of various restorative activities. Individuals act reciprocally within their environments to enhance or diminish the probability of experiencing stress. Restorative processes return individuals to baseline arousal levels and include retreating from daily stress, various relaxation behaviors, and sleep. Restorative activities play a significant role in the recovery from stress and presumably on the impact of stress on executive function abilities.

Being employed by multiple low-paying jobs with little flexibility and few available sick days and/or living arrangements that are not safe or not conducive to obtaining needed rest are likely to reduce individuals' opportunities to retreat from daily stress, engage in relaxation behaviors, and obtain restorative sleep. Poor sleep is itself associated with impaired immune function and all-cause mortality (Dew et al., 2003; Lange et al., 2003; McEwen, 1998). Individuals in lower SES groups get less sleep and the sleep is of poorer quality than individuals in higher SES groups (Moore et al., 2002; Van Cauter and Spiegel, 1999). High pre-sleep arousal is associated with poor executive function abilities, a strong prognostic indicator of sleep disruption and chronic sleep difficulties (Bastien et al., 2008). Poor sleep quality can cause significant decreases in mental flexibility, the ability to accurately identify stressors, and the ability to inhibit rumination (Williams et al., 2009). Environmental factors and learned behaviors can also limit opportunities to engage in adequate restorative activities.
What is the evidence of executive dysfunction among individuals who smoke cigarettes, are obese, abuse alcohol, and use illicit drugs?

A plethora of evidence has linked executive dysfunction to cigarette smoking, obesity, and alcohol and illicit drug use as well as the recovery from these conditions. Much of this evidence has been reviewed elsewhere. See Bickel et al. (2012) for a review of executive dysfunction in substance abuse by type of executive dysfunction and Blume and Marlatt (2009) for a review of the role of executive function in substance abuse recovery. Smith et al. (2011) provide a systematic review of the association between executive function and obesity across the lifespan. Raman et al. (2013) integrate executive function in a multifaceted model of clinical obesity. Thus, we provide a limited summary here.

Patterns of executive dysfunction are widely documented among adolescents, college students, adults, and older adults who smoke cigarettes (Cervilla et al., 2000; Richards and Sacker, 2003), and abuse alcohol (Alterman et al., 1984; Beatty et al., 1995; Bechara et al., 2001; Bickel et al., 1999; Chamberlain et al., 2012), cannabis, opiates, and stimulants (Beatty et al., 1995; Berry et al., 1993; Bickel et al., 2012). Excessive discounting of delayed rewards is associated with a poorer treatment response for some cigarette smokers (MacKillop and Kahler, 2009; Sheffer et al., 2012a; Washio et al., 2011) and alcoholics (Blume et al., 2005; Houben et al., 2011). Nonetheless, executive function appears to remain impaired well into recovery from alcohol abuse (Bates et al., 2005). Whether substance use causes executive dysfunction and/or is a pre-existing vulnerability for developing substance abuse is unclear.

Executive function abilities are associated with the development and maintenance of obesity in children, adolescents, and adults (Davis, 2004; Galioto et al., 2012; Guxens et al., 2009). Obese individuals show deficits in a wide variety of executive functions including attention (Cserjesi et al., 2009), behavioral flexibility (Cserjesi et al., 2009; Verdejo-García et al., 2009), behavioral inhibition (Maayan et al., 2011; Verdejo-García et al., 2009), planning/reflection impulsivity (Lokken et al., 2010), discounting of delayed rewards (Bickel et al., 2010; Epstein et al., 2010), working memory (Gunstad et al., 2007; Maayan et al., 2011), emotional information processing and initiating and maintaining goal-directed responding (Bonato and Boland, 1983). Greater discounting of delayed rewards is predictive of treatment outcome for obese children (Best et al., 2012). Although causal relations between obesity and executive dysfunction abilities may be reciprocal, the mechanisms by which obesity might result in executive dysfunction are, as yet, unclear.

\section{Discussion}

Based on our review of the literature, we found evidence that the SES gradient is associated with negative health behaviors and executive function abilities. We found evidence that SES is associated with stress regulation and that increased stress levels contribute to executive dysfunction. We also found evidence of significant executive dysfunction among individuals who smoke cigarettes, are obese, and abuse alcohol or illicit drugs. This associative evidence supports our proposal that the experience of SES affects executive function and the regulatory balance of the Competing Neurobehavioral Decision Systems; that is, SES diminishes the capacity for individuals to establish and follow through with immediate and delayed healthy decisions.

Most would agree that multiple factors play a role in the development and maintenance of these important health behaviors. Once a behavior becomes entrenched, the biological, behavioral, and psychological aspects feed back into the bio-behavioral system through multiple iterative and multidirectional processes that make altering the behavior difficult. Nonetheless, the executive decision system provides a potential target for intervention. Executive function abilities are becoming more prominent in empirical and conceptual investigations of these complex processes (Bickel et al., 2012; Blume and Marlatt, 2009). As noted above, executive dysfunction can result in dysregulation of the dual systems 
such that the impulsive decision system exerts greater influence than the executive decision system. This dysregulation could result in preference for immediate reinforcers consistent with choosing to smoke, over consume food and alcohol, and use illicit drugs, even when serious longterm adverse consequences may result. If executive function skills are not suitably developed or are dysfunctional, the result is greater difficulty in making optimal decisions in a wide variety of health-related situations as well as greater difficulty in achieving and maintaining good health.

The implications of this line of investigation are wide reaching. The prefrontal cortices, the primary seat of executive function abilities, are highly plastic and highly adaptive to extant conditions. This plasticity is consistent with the view that executive dysfunction is likely an adaption to environmental conditions and is a potential strength in treatments designed to improve executive function and its influence on health behavior (see Bickel et al., in press). The recognition of significant executive dysfunction among individuals who abuse alcohol and illicit substances, and use tobacco has generated interest in the use of executive function remediation strategies as part of treatment. For example, in a random assignment study, Bickel et al. (2011) examined the effects of working memory versus control training among individuals with stimulant abuse and dependence and found that working memory training improved the ability to value delayed outcomes. Similarly, Sheffer et al. (2013) used neuromodulatory brain stimulation of the dorsolateral prefrontal cortex to improve the value of delayed outcomes among smokers. Other studies have also documented the positive effects of working memory training on alcohol consumption and obesity treatment outcomes (Houben et al., 2011; Verbeken et al., 2013). At present, whether executive function interventions will result in longterm abstinence from substances and improve other health behaviors is unclear (Bickel et al., 2011; Blume and Marlatt, 2009). Most likely these techniques will need to be paired with cognitive-behavioral approaches to achieve optimum results. Additionally, interventions could be offered to children at an early age to improve executive function alone or as part of prevention efforts aimed at improving long-term health behaviors (c.f., Ramey et al., 2012). Considerable research remains to be conducted.

All of the health behaviors and conditions mentioned here are modifiable with standard cognitive-behavioral interventions, biofeedback, meditation, and other stress reduction techniques, but are particularly effortful for individuals with limited executive function abilities. Compliance and treatment outcomes could be improved by using contingency management to increase adherence with executive function interventions among alcohol and drug dependent individuals in treatment (Silverman et al., 2012), the obese (Jeffery, 2012) and individuals with other problematic health behaviors (Higgins et al., 2012).

Given that the effects of SES on executive function are a result of adaption to the local environment and circumstances and are amenable to change supports the consideration of social justice. Indeed, social justice is an important component of conceptualizing the various policy responses to SES disparities (Greenberg and Renne, 2005; see U.S. Environmental Protection Agency (EPA), 1998, pp 7-8 for a discussion of environmental justice). For example, Adler and Stewart (2010a) have advocated for behavioral justice, which we think may be more aptly referred to as resource justice; that is, they state, "that no group should bear a disproportionate share of health problems resulting from inadequate resources for engaging in healthy behaviors." (p. 12) (see also Adler and Stewart, 2009). We agree and wish to support another sense of what we call 'behavioral justice.' Specifically, we consider it unjust for an individual not to learn the skills or be provided the means and motivation to prevent, diminish, or change health risky behaviors. The extant evidence suggests that this necessarily includes the opportunity to achieve relative balance between the executive and impulsive decision systems that enable individuals to follow through with healthy choices as predicted by the Competing Neurobehavioral Decision Systems hypothesis. Such efforts would not only address behaviors that result in poor health and costly later stage interventions, but would also improve the quality of the lives of individuals at lower and middle segments of the SES gradient.

Conflict of interest statement

The authors declare that there are no conflicts of interest

\section{References}

Adler, N.E., Newman, K., 2002. Socioeconomic disparities in health: pathways and policies. Health Aff. 21, 60-76.

Adler, N.E., Rehkopf, D.H., 2008. U.S. disparities in health: descriptions, causes, and mechanisms. Annu. Rev. Public Health 29, 235-252.

Adler, N.E., Stewart, J., 2009. Reducing obesity: motivating action while not blaming the victim. Milbank Q. 87, 49-70.

Adler, N.E., Stewart, J., 2010a. Health disparities across the lifespan: meaning, methods, and mechanisms. Ann. N. Y. Acad. Sci. 1186, 5-23.

Adler, N.E., Stewart, J., 2010b. Using team science to address health disparities: MacArthur network as case example. Ann. N. Y. Acad. Sci. 1186, 252-260.

Agrawal, A., Sartor, C., Pergadia, M.L., Huizink, A.C., Lynskey, M.T., 2008. Correlates of smoking cessation in a nationally representative sample of U.S. adults. Addict. Behav. 33, 1223-1226

Alterman, A.I., Tarter, R.E., Petrarulo, E.W., Baughman, T.G., 1984. Evidence for impersistence in young male alcoholics. Alcohol. Clin. Exp. Res. 8, 448-450.

Anthony, J.C., Warner, L.A., Kessler, R.C., 1994. Comparative epidemiology of dependence on tobacco, alcohol, controlled substances, and inhalants: basic findings from the national comorbidity survey. Exp. Clin. Psychopharmacol. 2, 244-268.

Barbeau, E.M., Krieger, N., Soobader, M.J., 2004. Working class matters: socioeconomic disadvantage, race/ethnicity, gender, and smoking in NHIS 2000. Am. J. Public Health 94, 269-278.

Barrington, W.E., Beresford, S.A., McGregor, B.A., White, E., 2014. Perceived stress and eating behaviors by sex, obesity status, and stress vulnerability: findings from the vitamins and lifestyle (vital) study. J. Acad. Nutr. Diet. (in press).

Bastien, C.H., St-Jean, G., Morin, C.M., Turcotte, I., Carrier, J., 2008. Chronic psychophysiological insomnia: hyperarousal and/or inhibition deficits? An ERPs investigation. Sleep Res. Online 31, 887-898.

Bates, M.E., Voelbel, G.T., Buckman, J.F., Labouvie, E.W., Barry, D., 2005. Short-term neuropsychological recovery in clients with substance use disorders. Alcohol. Clin. Exp. Res. 29, 367-377

Baum II, C.L., Ruhm, C.J., 2009. Age, socioeconomic status and obesity growth. J. Health Econ. 28, 635-648.

Beatty, W.W., Katzung, V.M., Moreland, V.J., Nixon, S.J., 1995. Neuropsychological performance of recently abstinent alcoholics and cocaine abusers. Drug Alcohol Depend. 37, 247-253.

Bechara, A., 2005. Decision making, impulse control and loss of willpower to resist drugs: a neurocognitive perspective. Nat. Neurosci. 8, 1458-1463.

Bechara, A., Dolan, S., Denburg, N., Hindes, A., Anderson, S.W., Nathan, P.E., 2001. Decision-making deficits, linked to a dysfunctional ventromedial prefrontal cortex, revealed in alcohol and stimulant abusers. Neuropsychologia 39, 376-389.

Berry, J., van Gorp, W.G., Herzberg, D.S., et al., 1993. Neuropsychological deficits in abstinent cocaine abusers: preliminary findings after two weeks of abstinence. Drug Alcohol Depend. 32, 231-237.

Best, J.R., Theim, K.R., Gredysa, D.M., et al., 2012. Behavioral economic predictors of overweight children's weight loss. J. Consult. Clin. Psychol. 80, 1086-1096.

Bianchi, S.M., Milkie, M.A., 2010. Work and family research in the first decade of the 21st century. J. Marriage Fam. 72, 705-725.

Bickel, W.K., Marsch, L.A., 2001. Toward a behavioral economic understanding of drug dependence: delay discounting processes. Addiction 96, 73-86.

Bickel, W.K., Odum, A.L., Madden, G.J., 1999. Impulsivity and cigarette smoking: delay discounting in current, never, and ex-smokers. Psychopharmacology 146, 447-454.

Bickel, W.K., Jones, B.A., Landes, R.D., Christensen, D.R., Jackson, L., Mancino, M., 2010. Hypothetical intertemporal choice and real economic behavior: delay discounting predicts voucher redemptions during contingency-management procedures. Exp. Clin. Psychopharmacol. 18, 546-552.

Bickel, W.K., Yi, R., Landes, R.D., Hill, P.F., Baxter, C., 2011. Remember the future: working memory training decreases delay discounting among stimulant addicts. Biol. Psychiatry 69, 260-265.

Bickel, W.K., Jarmolowicz, D.P., Mueller, E.T., Gatchalian, K.M., McClure, S.M., 2012. Are executive function and impulsivity antipodes? A conceptual reconstruction with special reference to addiction. Psychopharmacology 221, 361-387.

Bickel, W.K., Quisenberry, A.J., Moody, L., Wilson, A.G., 2014. Therapeutic opportunities for self-control repair in addiction and related disorders: change and the limits of change in trans-disease processes. Clin. Psychol. Sci. http://dx.doi.org/ $10.1177 / 2167702614541260$ (in press).

Blume, A.W., Marlatt, G.A., 2009. The role of executive cognitive functions in changing substance use: what we know and what we need to know. Ann. Behav. Med. 37, $117-125$

Blume, A.W., Schmaling, K.B., Marlatt, G.A., 2005. Memory, executive cognitive function, and readiness to change drinking behavior. Addict. Behav. 30, 301-314

Bonato, D.P., Boland, F.J., 1983. Delay of gratification in obese children. Addict. Behav. 8, 71-74.

Buka, S.L., 2002. Disparities in health status and substance use: ethnicity and socioeconomic factors. Public Health Rep. 117, S118-S125. 
Centers for Disease Control and Prevention, 2005. Annual smoking-attributable mortality, years of potential life lost, and economic costs-United States, 1997-2001. Morb. Mortal. Wkly Rep. 54, 3.

Centers for Disease Control and Prevention, 2012. Behavioral Risk Factors Surveillance System: Comparability of Data (Atlanta).

Centers for Disease Control and Prevention, 2013. Behavioral Risk Factors Surveillance System: Comparability of Data (Atlanta).

Cervilla, J.A., Prince, M., Mann, A., 2000. Smoking, drinking, and incident cognitive impairment: a cohort community based study included in the Gospel Oak project. J. Neurol. Neurosurg. Psychiatry 68, 622-626.

Chamberlain, S.R., Odlaug, B.L., Schreiber, L.R., Grant, J.E., 2012. Association between tobacco smoking and cognitive functioning in young adults. Am. J. Addict. Am. Acad. Psychiatrists Alcohol. Addict. 21 (Suppl. 1), S14-S19.

Chan, R.C., Shum, D., Toulopoulou, T., Chen, E.Y., 2008. Assessment of executive functions: review of instruments and identification of critical issues. Arch. Clin. Neuropsychol. Off. J. Nat. Acad. Neuropsychologists 23, 201-216.

Cserjesi, R., Luminet, O., Poncelet, A.S., Lenard, L., 2009. Altered executive function in obesity. Exploration of the role of affective states on cognitive abilities. Appetite 52, 535-539.

Curran, G.M., Stoltenberg, S.F., Hill, E.M., Mudd, S.A., Blow, F.C., Zucker, R.A., 1999. Gender differences in the relationships among SES, family history of alcohol disorders and alcohol dependence. J. Stud. Alcohol 60, 825-832.

Cutler, D.M., Lleras-Muney, A., 2010. Understanding differences in health behaviors by education. J. Health Econ. 29, 1-28.

Davis, C.L., 2004. Highlights of NIDDK's translational diabetes and obesity research conference. Diabetes Technol. Ther. 6, 750-754.

Dew, M.A., Hoch, C.C., Buysse, D.J., et al., 2003. Healthy older adults' sleep predicts allcause mortality at 4 to 19 years of follow-up. Psychosom. Med. 65, 63-73.

Epstein, L.H., Salvy, S.J., Carr, K.A., Dearing, K.K., Bickel, W.K., 2010. Food reinforcement, delay discounting and obesity. Physiol. Behav. 100, 438-445.

Evans, J.S.B.T., Stanovich, K.E., 2013. Dual-process theories of higher cognition-advancing the debate. Perspect. Psychol. Sci. 8, 223-241.

Fagan, P., Shavers, V., Lawrence, D., Gibson, J.T., Ponder, P., 2007. Cigarette smoking and quitting behaviors among unemployed adults in the United States. Nicotine Tob. Res. Off. J. Soc. Res. Nicotine Tob. 9, 241-248.

Farah, M.J., Shera, D.M., Savage, J.H., et al., 2006. Childhood poverty: specific associations with neurocognitive development. Brain Res. 1110, 166-174.

Ferguson, J., Bauld, L., Chesterman, J., Judge, K., 2005. The English smoking treatment services: one-year outcomes. Addiction 100 (Suppl. 2), 59-69.

Fluss, J., Ziegler, J.C., Warszawski, J., Ducot, B., Richard, G., Billard, C., 2009. Poor reading in french elementary school: the interplay of cognitive, behavioral, and socioeconomic factors. J. Dev. Behav. Pediatr. 30, 206-216.

Galioto, R., Spitznagel, M.B., Strain, G., et al., 2012. Cognitive function in morbidly obese individuals with and without binge eating disorder. Compr. Psychiatry 53, 490-495.

Gallo, L.C., Matthews, K.A., 2003. Understanding the association between socioeconomic status and physical health: do negative emotions play a role? Psychol. Bull. 129, 10-51.

Galobardes, B., Shaw, M., Lawlor, D.A., Lynch, J.W., Davey Smith, G., 2006a. Indicators of socioeconomic position (part 1). J. Epidemiol. Community Health 60, 7-12.

Galobardes, B., Shaw, M., Lawlor, D.A., Lynch, J.W., Davey Smith, G., 2006b. Indicators of socioeconomic position (part 2). J. Epidemiol. Community Health 60, 95-101.

Goodman, E., Huang, B., 2002. Socioeconomic status, depressive symptoms, and adolescent substance use. Arch. Pediatr. Adolesc. Med. 156, 448-453.

Green, L., Myerson, J., Lichtman, D., Rosen, S., Fry, A.F., 1996. Temporal discounting in choice between delayed rewards: the role of age and income. Psychol. Aging 11, 79-84.

Greenberg, M.R., Renne, J., 2005. Where does walkability matter the most? An environmental justice interpretation of New Jersey data. J. Urban Health Bull. N. Y. Acad. Med. 82, 90-100.

Gunstad, J., Paul, R.H., Cohen, R.A., Tate, D.F., Spitznagel, M.B., Gordon, E., 2007. Elevated body mass index is associated with executive dysfunction in otherwise healthy adults. Compr. Psychiatry 48, 57-61.

Guxens, M., Mendez, M.A., Julvez, J., et al., 2009. Cognitive function and overweight in preschool children. Am. J. Epidemiol. 170, 438-446.

Hackman, D.A., Farah, M.J., 2009. Socioeconomic status and the developing brain. Trends Cogn. Sci. 13, 65-73.

Hackman, D.A., Farah, M.J., Meaney, M.J., 2010. Socioeconomic status and the brain: mechanistic insights from human and animal research. Nat. Rev. Neurosci. 11, 651-659.

Harder, V.S., Chilcoat, H.D., 2007. Cocaine use and educational achievement: understanding a changing association over the past 2 decades. Am. J. Public Health 97, 1790-1793.

Hart, B., Risely, T.R., 1995. Meaningful Differences in the Everyday Experiences of Young American Children. Brookes Publishing Co., Baltimore.

Higgins, S.T., Silverman, K., Sigmon, S.C., Naito, N.A., 2012. Incentives and health: an introduction. Prev. Med. 55 (Suppl.), S2-S6.

Houben, K., Wiers, R.W., Jansen, A., 2011. Getting a grip on drinking behavior: training working memory to reduce alcohol abuse. Psychol. Sci. 22, 968-975.

Jackson, J.S., Knight, K.M., Rafferty, J.A., 2010. Race and unhealthy behaviors: chronic stress, the HPA axis, and physical and mental health disparities over the life course. Am. J. Public Health 100, 933-939.

Jaroni, J.L., Wright, S.M., Lerman, C., Epstein, L.H., 2004. Relationship between education and delay discounting in smokers. Addict. Behav. 29, 1171-1175.

Jeffery, R.W., 2012. Financial incentives and weight control. Prev. Med. 55, S61-S67 (Suppl.)

Jentsch, J.D., Taylor, J.R., 1999. Impulsivity resulting from frontostriatal dysfunction in drug abuse: implications for the control of behavior by reward-related stimuli. Psychopharmacology 146, 373-390.
Jha, P., Peto, R., Zatonski, W., Boreham, J., Jarvis, M.J., Lopez, A.D., 2006. Social inequalities in male mortality, and in male mortality from smoking: indirect estimation from national death rates in England and Wales, Poland, and North America. Lancet 368 367-370.

Juster, R.P., McEwen, B.S., Lupien, S.J., 2010. Allostatic load biomarkers of chronic stress and impact on health and cognition. Neurosci. Biobehav. Rev. 35, 2-16.

Kandel, D.B., Griesler, P.C., Schaffran, C., 2009. Educational attainment and smoking among women: risk factors and consequences for offspring. Drug Alcohol Depend. 104, S24-S33.

Kanjilal, S., Gregg, E.W., Cheng, Y.J., et al., 2006. Socioeconomic status and trends in disparities in 4 major risk factors for cardiovascular disease among US adults, 1971-2002. Arch. Intern. Med. 166, 2348-2355.

Kitagawa, E., Hauser, P., 1973. Differential Mortality in the United States. Harvard University Press, Cambridge, MA.

Kotz, D., West, R., 2009. Explaining the social gradient in smoking cessation: it's not in the trying, but in the succeeding. Tob. Control. 18, 43-46.

Lange, T., Perras, B., Fehm, H.L., Born, J., 2003. Sleep enhances the human antibody response to hepatitis a vaccination. Psychosom. Med. 65, 831-835.

Lee, N.C., de Groot, R.H., Boschloo, A., Dekker, S., Krabbendam, L., Jolles, J., 2013. Age and educational track influence adolescent discounting of delayed rewards. Front Psychol. 4, 993.

Lipina, S.J., Martelli, M.I., Colombo, J.A., 2005. Performance on the a-not-b task of Argentinean infants from unsatisfied and satisfied basic needs homes. Revista Interamericana de Psicología (Interam. J. Psychol.) 39, 49-60.

Lokken, K.L., Boeka, A.G., Yellumahanthi, K., Wesley, M., Clements, R.H., 2010. Cognitive performance of morbidly obese patients seeking bariatric surgery. Am. Surg. 76, 55-59.

Maayan, L., Hoogendoorn, C., Sweat, V., Convit, A., 2011. Disinhibited eating in obese adolescents is associated with orbitofrontal volume reductions and executive dysfunction. Obesity 1382-1387 (July).

MacKillop, J., Kahler, C.W., 2009. Delayed reward discounting predicts treatment response for heavy drinkers receiving smoking cessation treatment. Drug Alcohol Depend. 104, 197-203.

Makela, P., 1999. Alcohol-related mortality as a function of socio-economic status. Addiction 94, 867-886.

Mani, A., Mullainathan, S., Shafir, E., Zhao, J., 2013. Poverty impedes cognitive function. Science 341, 976-980.

Marmot, M.G., Shipley, M.J., Rose, G., 1984. Inequalities in death-specific explanations of a general pattern? Lancet 1, 1003-1006.

McEwen, B.S., 1998. Stress, adaptation, and disease. Allostasis and allostatic load. Ann. N. Y. Acad. Sci. 840, 33-44.

McGinnis, J.M., Foege, W.H., 1993. Actual causes of death in the United States. JAMA 270, 2207-2212.

Miech, R.A., Hauser, R.M., 2001. Socioeconomic status and health at midlife. A comparison of educational attainment with occupation-based indicators. Ann. Epidemiol. 11, 75-84.

Mokdad, A.H., Marks, J.S., Stroup, D.F., Gerberding, J.L., 2004. Actual causes of death in the United States, 2000. JAMA 291, 1238-1245.

Moore, P.J., Adler, N.E., Williams, D.R., Jackson, J.S., 2002. Socioeconomic status and health: the role of sleep. Psychosom. Med. 64, 337-344.

National Institute on Drug Abuse, 2012. DrugFacts: Understanding Drug Abuse and Addiction (Washington, D.C.).

National Research Council, 2013. U.S. Health in International Perspective: Shorter Lives, Poorer Health. The National Academies Press, Washington, D. C.

Noble, K.G., McCandliss, B.D., Farah, M.J., 2007. Socioeconomic gradients predict individual differences in neurocognitive abilities. Dev. Sci. 10, 464-480.

Parker, D.A., Harford, T.C., 1992. The epidemiology of alcohol consumption and dependence across occupations in the United States. Alcohol Health Res. World 16, 97-105.

Perkins, S.C., Finegood, E.D., Swain, J.E., 2013. Poverty and language development: roles of parenting and stress. Innov. Clin. Neurosci. 10, 10-19.

Raman, J., Smith, E., Hay, P., 2013. The clinical obesity maintenance model: an integration of psychological constructs including mood, emotional regulation, disordered overeating, habitual cluster behaviours, health literacy and cognitive function. J. Obes. 2013, 240128.

Ramey, C.T., Sparling, J.L., Ramey, S.L., 2012. Abecedarian: The Ideas, the Approach, and the Findings. Sociometrics Corporation, Los Altos, CA.

Reid, R.D., Mullen, K.A., Slovinec D'Angelo, M.E., et al., 2010. Smoking cessation for hospitalized smokers: an evaluation of the "Ottawa Model". Nicotine Tob. Res. Off. J. Soc. Res. Nicotine Tob. 12, 11-18.

Reimers, S., Maylor, E.A., Stewart, N., Chater, N., 2009. Associations between a one-shot delay discounting measure and age, income, education and real-world impulsive behavior. Personal. Individ. Differ. 47, 973-978.

Richards, M., Sacker, A., 2003. Lifetime antecedents of cognitive reserve. J. Clin. Exp. Neuropsychol. 25, 614-624.

Richards, M., Wadsworth, M.E., 2004. Long term effects of early adversity on cognitive function. Arch. Dis. Child. 89, 922-927.

Rimm, E.B., Williams, P., Fosher, K., Criqui, M., Stampfer, M.J., 1999. Moderate alcohol intake and lower risk of coronary heart disease: meta-analysis of effects on lipids and haemostatic factors. BMJ 319, 1523-1528 (Clinical Research Ed.).

Schroeder, S.A., 2007. We can do better-improving the health of the American people. N. Engl. J. Med. 357, 1221-1228.

Schulz, A.J., Mentz, G., Lachance, L., Johnson, J., Gaines, C., Israel, B.A., 2012. Associations between socioeconomic status and allostatic load: effects of neighborhood poverty and tests of mediating pathways. Am. J. Public Health 102, 1706-1714.

Shavers, V.L., 2007. Measurement of socioeconomic status in health disparities research. J. Natl. Med. Assoc. 99, 1013-1023. 
Sheffer, C.E., MacKillop, J., McGeary, J., et al., 2012a. Delay discounting, locus of control, and cognitive impulsiveness independently predict tobacco dependence treatment outcomes in a highly dependent, lower socioeconomic group of smokers. Am. J. Addict. 21, 221-232.

Sheffer, C.E., Stitzer, M., Landes, R., Brackman, S.L., Munn, T., Moore, P., 2012b. Socioeconomic disparities in community-based treatment of tobacco dependence. Am. J. Public Health 102, e8-e16.

Sheffer, C.E., Mennemeier, M., Landes, R.D., et al., 2013. Neuromodulation of delay discounting, the reflection effect, and cigarette consumption. J. Subst. Abus. Treat. 45, 206-214.

Silverman, K., DeFulio, A., Sigurdsson, S.O., 2012. Maintenance of reinforcement to address the chronic nature of drug addiction. Prev. Med. 55, S46-S53 (Suppl.).

Smith, P.J., Blumenthal, J.A., Babyak, M.A., Hinderliter, A., Sherwood, A., 2011. Association of vascular health and neurocognitive performance in overweight adults with high blood pressure. J. Clin. Exp. Neuropsychol. 33, 559-566.

Sobal, J., Stunkard, A.J., 1989. Socioeconomic status and obesity: a review of the literature. Psychol. Bull. 105, 260-275.

Strack, F., Deutsch, R., 2004. Reflective and impulsive determinants of social behavior. Personal. Soc. Psychol. Rev. Off. J. Soc. Personal. Soc. Psychol. Inc. 8, 220-247.

Trinidad, D.R., Perez-Stable, E.J., White, M.M., Emery, S.L., Messer, K., 2011. A nationwide analysis of US racial/ethnic disparities in smoking behaviors, smoking cessation, and cessation-related factors. Am. J. Public Health 101, 699-706.

U.S. Department of Health and Human Services, 2001. Overweight and obesity: a major public health issue. Prevention Report.

U.S. Environmental Protection Agency (EPA), 1998. Guidance for Incorporating Environmental Justice Concerns in EPA's NEPA Compliance Analyses (Washington, D. C.)

Van Cauter, E., Spiegel, K., 1999. Sleep as a mediator of the relationship between socioeconomic status and health: a hypothesis. Ann. N. Y. Acad. Sci. 896, 254-261. van Oers, J.A., Bongers, I.M., van de Goor, L.A., Garretsen, H.F., 1999. Alcohol consumption, alcohol-related problems, problem drinking, and socioeconomic status. Alcohol Alcohol. 34, 78-88.

Varghese, M., Sheffer, C.E., Stitzer, M., Landes, R., Brackman, S.L., Munn, T., 2014. Socioeconomic disparities in community-based treatment of tobacco dependence. Am. J. Public Health e1-9. (e-pub ahead of print).

Verbeken, S., Braet, C., Goossens, L., van der Oord, S., 2013. Executive function training with game elements for obese children: a novel treatment to enhance selfregulatory abilities for weight-control. Behav. Res. Ther. 51, 290-299.

Verdejo-García, A., Pérez-Expósito, M., Schmidt-Río-Valle, J., et al., 2009. Selective alterations within executive functions in adolescents with excess weight. Behav. Psychol. $18,1572-1578$.

Wardle, J., Waller, J., Jarvis, M.J., 2002. Sex differences in the association of socioeconomic status with obesity. Am. J. Public Health 92, 1299-1304.

Washio, Y., Higgins, S.T., Heil, S.H., et al., 2011. Delay discounting is associated with treatment response among cocaine-dependent outpatients. Exp. Clin. Psychopharmacol. $19,243-248$.

Wetter, D.W., Cofta-Gunn, L., Fouladi, R.T., et al., 2005. Understanding the associations among education, employment characteristics, and smoking. Addict. Behav. 30, 905-914.

Wilkinson, R., Pickett, K., 2011. Greater equality: the hidden key to better health and higher scores. Am. Educ. 5-9 (Spring).

Williams, L.M., Gatt, J.M., Schofield, P.R., Olivieri, G., Peduto, A., Gordon, E., 2009. 'Negativity bias' in risk for depression and anxiety: brain-body fear circuitry correlates, 5HTT-LPR and early life stress. NeuroImage 47, 804-814. 